University of Nebraska - Lincoln

DigitalCommons@University of Nebraska - Lincoln

To Improve the Academy

Professional and Organizational Development Network in Higher Education

1995

Using Electronic Mail for Teaching and Learning

James M. Hassett

Charles M. Spuches

Sarah P. Webster

Follow this and additional works at: https://digitalcommons.unl.edu/podimproveacad

Part of the Higher Education Administration Commons

Hassett, James M.; Spuches, Charles M.; and Webster, Sarah P., "Using Electronic Mail for Teaching and Learning" (1995). To Improve the Academy. 333.

https://digitalcommons.unl.edu/podimproveacad/333

This Article is brought to you for free and open access by the Professional and Organizational Development Network in Higher Education at DigitalCommons@University of Nebraska - Lincoln. It has been accepted for inclusion in To Improve the Academy by an authorized administrator of DigitalCommons@University of Nebraska - Lincoln. 


\section{Using Electronic Mail for Teaching and Learning}

\section{James M. Hassett}

SUNY College of Environmental Science and Forestry

\section{Charles M. Spuches}

SUNY College of Environmental Science and Forestry

\section{Sarah P. Webster}

SUNY College of Environmental Science and Forestry

Electronic mail (e-mail) can be a useful educational tool that can enhance learning in any curriculum. This article will provide instructors with a conceptual framework and several examples of how e-mail can be integrated into a variety of classroom and independent learning situations.

As a cost effective and accessible communications tool, e-mail makes a significant impact on communications within and across college and university campuses and has become a vehicle for finding and using information resources. While the use of e-mail for all communications is growing rapidly, few materials are readily available for faculty who want to use e-mail as an educational tool. Thus, we have not yet realized the potential of e-mail to enhance learning and to integrate this type of computing into the whole curriculum.

We hope this article will encourage faculty to incorporate this new application of computer technology into the teaching and learning process. 


\section{Why Use E-mail?}

Although computing in general, and e-mail in particular, are well established in undergraduate education, they are not fully integrated into the curriculum. We often limit computing to courses in which it is the primary focus or a necessary tool, such as computer programming or statistics courses. The notion of integrating e-mail into the undergraduate curriculum as an instructional tool is still relatively new, but introducing e-mail into any curriculum has many potential benefits.

Students and faculty both benefit from using e-mail. Students learn a communication tool that is used throughout academia and industry. Using e-mail is the first step in using the Internet, the international research and education network that our students can navigate by using network searching tools.

Students who use e-mail find that faculty are accessible for more than posted office hours. E-mail extends office hours to virtually any time and place, to the mutual convenience of faculty and students. Students also can discover and learn to use educational resources that exist beyond the boundaries of the campus.

E-mail allows students and faculty to join other learners of all ages, from all over the globe, in discussions of mutual educational interest. This enlarged "peer group" brings together people from other cultures, religions, educational systems, and political systems, enriching students on the local campus.

Finally, students are encouraged to learn independently and are rewarded for doing so. The educational networks are so enticing that students often explore them beyond the requirements of a particular course.

Each of our courses has a specific goal and objectives according to its place in the overall college curriculum. E-mail has proven useful for communicating these details to our students. More broadly, we want to introduce our students to the notion that their intellectual efforts constitute part of a worldwide community of teaching and learning - learning that goes on far beyond the confines, in time and space, of a classroom. We can empower our students by giving them access to electronically stored information. It is important to discuss 
protocols for using an electronic network, as well as to consider the ethical issues inherent in using it. In short, we want to produce literate citizens of the worldwide networks, and e-mail is a starting point.

\section{Putting E-mail to Use}

The conceptual framework we developed to organize examples of e-mail use is represented in figure 1 . There are many ways to portray uses for e-mail. We all have our own mental maps of the teaching and learning process, and this is true for the use of technology such as e-mail as well. The reader should not, therefore, treat this framework as the last word, but rather as a starting point. Use it for critical consideration of how you use or might use e-mail in your own teaching. Then, adapt or extend this framework as your experiences and needs suggest.

Figure 1: A Framework for E-mall Use in Teaching and Learning

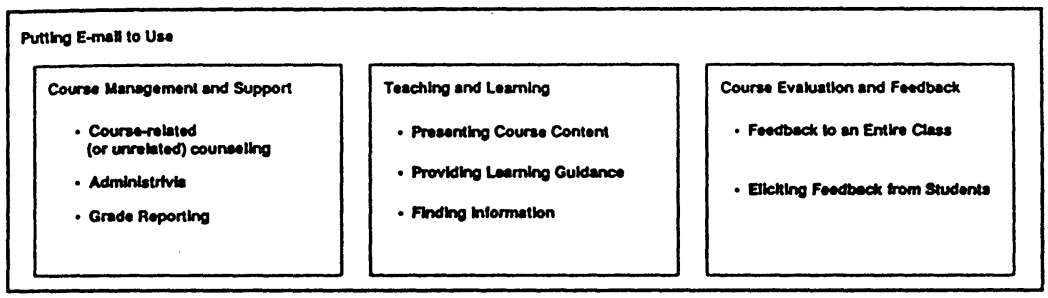

The examples of e-mail use in this article are derived from our experience with a mainframe computer and are based upon its unique operating and mail systems. Other e-mail packages on other systems typically have similar functions but different details. While the examples used here represent one particular format, we emphasize that the functions discussed here are not specific to particular computer systems.

One obvious point bears mentioning. The following framework and examples of e-mail use in instruction are based on the premise that 
everybody concerned owns or has access to a computer. Whether students own or lease computers loaded with the necessary software or use campus computer clusters, easy access to e-mail is a prerequisite to its use as an instructional tool.

\section{Course Management and Support}

\section{Course-related (or unrelated) counseling}

All of us know students who are dealing with events in their personal lives that interfere with their studies. Sometimes we think a student needs specific help right away.

A male student in Dr. White's course comes up to the professor after class to explain why he will be late handing in a paper. His father is dying, and his mother is having trouble. The student goes home every weekend to help his mother and brothers and sisters. It's clear this young man will have a rough semester. White sends this message.

Date:19 Oct. 1994, 14:29:44 EST

From:Dr. White <WHITE@SUVM>

To:Phil Koerner <KOERNER@SUVM>

Subject:Your paper

Thanks for letting me know about the late paper. This is your "official" confirmation that I've extended your deadline until October 26.

I'm sorry about your father. I lost my own father two years ago, and even though I'm much older than you, it was very hard to realize I could never ask his advice again. Let me know if I can do anything else to help you. 


\section{Administrivia}

E-mail can be a useful tool for communicating day-to-day announcements that facilitate student progress in our courses. Consider the following scenarios.

Professor Johnson wants to make sure all her students know who the teaching assistant is and how to reach him for help. She could follow up an announcement in class with a message like this:

FROM:SUNRIS::WJOHNSON 1-SEP-1994 09:32:37.06

TO:@users

\section{CC:CMOORE}

SUBJECT: Teaching Assistant

Our teaching assistant this semester is Clark Moore. His office is $410 \mathrm{a}$ Bray Hall. His office hours will be Wednesday and Thursday 9-10 a.m. or by appointment. His phone extension is 6664 , or e-mail may be addressed to him via cmoore@mailbox or cmoore@suvm.

In this example, the @ users on the TO line shows that all computer users registered for this class will have received the identical message - except that their computer userid (their personal e-mail address) will appear instead of the @ user. This requires Professor Johnson to create the proper file of userids in her master account.

Professor Johnson also might wish to communicate course announcements as she learns of them rather than waiting for the next class meeting, as the following example suggests.

From:SUNRIS::WJOHNSON 03-SEP-1994 16:06:24.32

To:@users

CC:

Subj:Course reader ready 
I have just learned that the course reader of assigned labs and suggested (for undergraduates) and required (for graduate students) articles is ready. You may purchase the reader at the campus copy center in the Campus Mall. Ask for reader number 338. Please have the reader in hand for your first lab session.

\section{Grade Reporting}

Most students want to know their grades for examinations and assignments as soon as possible. E-mail can provide quick dissemination of grades as soon as they are known, freeing valuable class time for other uses. Performance messages can also focus the student's attention on issues raised by her or the class's performance on the exam rather than on the grade alone.

Assistant Professor Wheeler teaches 40 students in a required junior-level course. He has just given one of three course examinations. As soon as he knows the results, after finishing the grading at home, he sends the following messages to the students in his class.

From:SUNRIS::GWHEELER 29-FEB-1994 20:18:08.24

To:@users

SUBJECT:Exam 1 Grades

The grades on the first examination in Forestry 323 ranged from a low of 28 to a high of 97 . The mean grade was 72.8 with a standard deviation of 14.3. Most students mischaracterized stem cambial growth patterns in answers to the questions at the end of Part B. While this is not a course in cellular botany, these patterns are important because they determine wood characteristics. If you feel rusty on this topic, review pages 68 through 74 in your textbook.

Your grade will be in the next mail message in your reader.

Feel free to ask any questions you may have in class or during my office hours (Wednesday and Friday afternoons from 3 p.m. to 4 p.m.). You may, of course, send an e-mail anytime.

Until later - Gordon Wheeler. 
At times it may be appropriate or necessary to contact an individual student, as in the following example. An extra word of encouragement to a student who has had difficulty will be appreciated. On the other hand, e-mail is an unobtrusive way to focus a student's attention on less than satisfactory attendance or performance. E-mail is a convenient way to schedule or reschedule individual conferences with students.

From:SUNRIS::GWHEELER 29-FEB-1994 20:21:54.02

To:SUNRIS::RAROE

SUBJECT:

Your grade was 92. Excellent! I know you were concerned after your last exam but you're doing well. It looks like your study group and initiative have helped.

\section{Teaching and Learning}

\section{Presenting Course Content}

It's easy to forget to hand out information in class. Moreover, you may prefer to spend class time having students work on problems rather than listen to lectures. We've often used e-mail to disseminate new information and to correct misinformation.

On Thursday, Professor Miller's class became so involved in problem-solving that he decided not to interrupt them to introduce the next topic. However, he didn't want to wait for the next lecture, five days later. So he decided to introduce the topic electronically.

Date:16 Nov 1994, 11:45:45 EST

From:Peter Miller <MILLER@SUVM>

To:ENG645@SUVM

The next topic we'll discuss is the electric properties of dilithium crystals and their part in the warp drives of starships. Warp drives are 
the third propulsion system we are considering this semester (the other two are ramjet engines and scoopjet engines). Please read the chapter on warp drives for Tuesday's class. By the way, good discussion today.

Professor Anderson has been reading papers written by the Scientific Writing class and she's drowning in misplaced modifiers. She'd hoped not to have to use time discussing grammar with college juniors; however, if she sees too many more of these, she'll go nuts. Moreover, it's important in any writing course to remediate or reinforce student ability to write clearly. She sends this message to the class.

Date:19 Sep 1994, 13:13:13 EST

From:Morgan Anderson ANDERSON@SUVM

To:WRT444

Subject:Misplaced Modifiers

I've been reading the most recent set of papers, and there's an issue we have to address - namely, misplaced modifiers.

Definition: Misplaced Modifier - a word, phrase, or clause which is so badly placed in a sentence that it's not clear what word it is defining or elaborating.

Examples:

1. Coming up out of the subway, the sun hit me in the eye.

"Coming up out of the subway" is the modifier. It is supposed to refer to the person coming up out of the subway (maybe "I"). Instead, because of where it is placed in the sentence, it actually refers to "the sun." So I have this picture of the sun riding the $A$ train.

Sentence corrected:

"Coming up out of the subway, I was blinded by the sun hitting me in the eye." or

"As I came up out of the subway, the sun hit me in the eye."

2. If locked, please see the secretary for the key. 
The modifier is "If locked" and probably refers to a door. However, because of where it's placed in the sentence, it appears to refer to "you" which is the understood subject of the next clause "please (you) see the secretary for the key." So what the sentence really says is "If you are locked, please..."

Use another word or two to be precise: "If the door is locked, please see..."

You may want to try the fatuous argument that "everybody knows what I mean," but don't! This is the course where you learn to write precisely what you mean, so the reader does not have to translate.

Expect an exercise during the next class on rewriting sentences to get rid of misplaced modifiers. Your text has a section in the back about this. Please review it.

Assistant Professor Jones is in a quandary. He offers a seminar in his specialty but finds no suitable textbooks available. He could spend hours composing assignments, proofreading them and making revisions before having them copied for the students in his class. Rather than use this route, Jones chooses to e-mail the bulk of the material to his students. Consider the following examples.

From:SUNRIS::WJONES 08-SEP-1994 21:33:35.38

TO: @users

CC:

Subj:Second problem assignment

The following problems are due one week from today.

Problem 4.

Discuss.....

Problem 5.

Discuss.....

Professor Jones can also respond to questions that arise in class or office hours via e-mail. This way the entire class benefits from the discussion. 
From:SUNRIS::WJONES 25-SEP-1994 14:33:02.04

To:@users

CC:

Subj:Hint on problem 16.

A question in class concerned proving that critical flow implies maximum discharge for a given specific energy. Here's a hint: write the energy equation for a channel of arbitrary geometry, i.e., in terms of $Q$ and $\mathrm{A}$.

\section{Providing Learning Guidance and Feedback}

E-mail messages can provide reminders of, and guidance for, exams. Each student receives an individual message regardless of whether or not they were in class. Professor Johnson might well choose to send a message similar to the following example.

From:SUNRIS::WJOHNSON 25-OCT-92 15:27:41.12

To:@users

CC:

Subj:Better get ready!

We will have a quiz on Thursday, October 30,1994. The quiz will be based on a problem similar to problem 52 . The quiz may well involve:

Calculation of critical energy.

Calculation of normal depth.

Identification of hydraulic controls.

Identification of flow profiles.

Calculation of flow profiles for regular channels.

You will want to solve and think about problem 52. For example, can you, after having solved the problem, relate the profiles to the E-y 
diagram? Can you draw the conjugate depth curve? Can you relate the data in the problem to the M-y curve, i.e., locate the profiles, locate the hydraulic jump, etc.? Such will be the nature of the quiz!

Professor Johnson soon finds that some of her students use e-mail to ask for help on certain assignments. She sets aside a few minutes each day to answer queries, as illustrated in the following example, hoping that the time spent composing replies to these messages will be offset by fewer visitors during formal office hours.

From:SUNRIS::EBWHITE 12-0CT-1994 17:33:52.56

To:WJOHNSON

CC:

Subj:\#27

How about a helpful hint on problem $27 ?$

Is it simply algebraic manipulation or do we have to ASSUME something?

In this example, Professor Johnson recognizes the userid (EBWHITE) as belonging to a somewhat shy student who had not come to office hours for help. She responded with an appropriate hint and the student was able to proceed with the problem assignment.

\section{Finding Information}

Sometimes local information resources are not robust enough for a student research project. In the past, this and the tendency of some students to put off their work has led to poor or late results, with the explanation (excuse?) that "it wasn't possible to get information about this unusual subject in time." We use the computer networks to gain access to information housed elsewhere, removing obstacles of time and place and showing students how to reach beyond the boundaries of the campus.

The seniors in Professor Robinson's class have used the library resources of the college and neighboring colleges extensively, but a 
few of them cannot find enough information on the topics they've chosen for research papers. As usual, they have delayed starting their projects so long that Interlibrary Loan cannot come to the rescue. Professor Robinson belongs to an electronic interest group, and he remembers that one of the subscribers informed the group that a large group of documents in the field had been put on a public file server at her institution, available to students and scholars alike. Robinson gets an index of the documents and instructions for retrieving them and sends the following message.

Date:Wed, 10 Nov 1994 11:11:11 EDT

From:Jim Robinson <ROBINSON@SUVM>

To:Tom Mason <TMASON@SUVM>, Dick Smith <DSMITH@SUVM>, Harriet Wilkins <HWILKINS@SUNRISE>

Subject:Information for your research papers

OK. I have a list of some articles you can get for your research papers. Come to my office hours THIS WEEK and let's look the list over. I'll teach you how to get the articles if you're interested. Do not wait!

For a course in industrial policy, Professor Ortiz wants her students to work in teams, something she's never tried before. She can't do a first-class literature search on this technique in the few weeks remaining before classes begin. She decides to use computer networks to ask for advice from others with more experience. She belongs to several electronic interest groups, but wants to ask people in other groups as well. So she uses the network to get a list of all possible lists.

Date:14 Aug, 1994 10:10:10 EDT

From:Maria Ortiz <ORTIZ@SUVM>

To:LISTSERV@BITNIC

list global 
This mail message activates a piece of software at the BITNET Information Center which sends back a global list of all electronic interest groups on BITNET.

When she receives the master list, Ortiz sends e-mail to a halfdozen of them, asking for help.

Date:15 Aug, 1994 16:35:59 EDT

From:Maria Ortiz<ORTIZ@SUVM>

To:POLITICS@UBVM, PUBPOL-L@NDSUVM1, HISTORY@YALEVM, TEACHTEC@IUBVMS, HUMANIST@BROWNVM, POLISCI@TAUNIVM

I'm teaching an upper-division course in public policy starting in September. The class is very large, and I'd like to have the students work in teams. I've never tried this before, and I'm not sure how to do it: what to avoid, what to try. I'd like some advice from any of you who have tried it.

In 48 hours, she's received long mail messages from eight faculty members (all from different institutions), and she has specific suggestions, warnings, names of others to contact, and titles of articles and books she can read.

\section{Course Evaluation and Feedback}

As teachers, we ask students to comment on and evaluate us and our courses in many ways. The college asks for anonymous general comments at the end of each semester. Some of us also ask for specific comments on the content and organization of individual courses. Most of this evaluation is done on paper and is anonymous. It helps us revise the course for its next offering. However, it's possible to use e-mail to get ongoing information from students about a course as it is progresses.

Because e-mail is not necessarily anonymous (user identifications typically accompany e-mail messages), students must be confident that anything they say will not be used against them. 


\section{Feedback to an Entire Class}

The students in Professor Brown's class appear to be struggling. He sees too many glassy eyes and frowns, but he's not sure what the problem is. Could it be the pace? The new text? The problem sets? Rather than take up 15 or 20 minutes in class, he sends this message to the class.

Date:22 Oct 1994, 19:44:10 EST

From:Brown <BROWN@SUVM>

To:APM500

Subject:Problems?

I'm starting to worry about you folks. I see a lot of strained expressions and puzzled looks. When I ask for questions or comments, you're not talking. This is particularly true over the last two weeks. Please, tell me what's going on.

It's true I'm moving pretty fast. Too fast?

The text is new this year, written by one of the experts in the field. Is it readable? Shall I put some other information on reserve?

The problem sets are not trivial, but then, this is a 500-level course, so I think I can give some tough ones.

Maybe I haven't even guessed what the trouble is. Heavy course loads? Personal problems? What?

Please give me some information. You can come see me at office hours or send mail this way. Remember, neither method is anonymous. If you'd prefer, leave an unsigned paper message in my mailbox. Thanks.

\section{Eliciting Feedback from Students}

For the first time, Professor Olsen has broken her class into teams whose members are supposed to help each other work problems and study for exams. The law of averages suggests that some teams will not work very well. Which ones are they? Should she intervene? 
Counsel the team leaders? Change the responsibilities of the teams? She sends the team leaders a message.

Date:01 Oct 1994, 09:09:09 EST

From:H. Olsen HOLSEN@SUVM

To:LEADERS

Subject:Teams \& how they're working

I'd like some information from you on how the teams are working out. As you recall, I formed them by generating random numbers, so people were put together without regard for major, gender, eye color or any other criterion.

Could you please send answers THIS WEEK to these questions:

1. Is your team getting together to study? If not, why not?

2. Are you having any leadership troubles? If so, why is that, do you think? How can I help?

3. If I could do one single thing to make your team work more effectively, what would it be?

Please also tell me anything else you think I need to know about your team or about the team structure. Thanks.

\section{Tips for Introducing E-mail to the Classroom}

We hope we have piqued your interest and that you are ready to join the community of electronic teachers and learners. If you are not an e-mail user yourself, we recommend that you learn and use it regularly for at least a semester before you introduce it to students. If you have a choice of mail systems, you need to choose one. Talk to colleagues and find out which e-mail system they use. It's always good to have people nearby who can help you when you're getting started. Ask them to show you how their systems work, not so much to learn how to use them, but to see how they look. 
Look for organizational help to learn the system of your choice. The academic computing organizations often give short, free workshops on popular software. Sometimes they give away documentation with which you can teach yourself. Call or visit your computing organizations (including faculty support centers) to find out what help is available.

If you use e-mail for your own research or for keeping in touch with colleagues elsewhere in the world, it is relatively easy to expect your students to learn and to use it in your courses. The major changes you need to make are figuring out when and how to introduce it to your students, changing some of your own class management practices to make use of it, and, perhaps, learning some of the advanced features that make classroom use efficient - such as sending messages to groups. We think you should be able to make these changes within one semester.

When you introduce e-mail in the classroom, you need to help students get their e-mail accounts. Unless a student has a great deal of experience on another system, arrange for all students to use the same system you do. Start early to set up class or individual accounts, especially for the fall semester, because there is a high demand for computer accounts during the first few weeks of the academic year.

You should make sure you and your students can do the fundamentals, no matter what mail system you choose. If your academic computing organization gives away information on using the mail system, use that to teach students the fundamentals. In our courses, we have extracted the relevant information from such sources and made handouts for our own students. You might want to do that if the original covers many more topics than the fundamentals or if you want to give students a quick reference guide. A progression of basic to advanced e-mail skills is suggested in figure 2 .

While you're teaching e-mail fundamentals, be sure to stress the network guidelines for responsible mail and network use. You can get these guidelines from the computing organizations and from the networks themselves. We all learned at home not to read someone else's mail or to listen in on others' telephone calls. Our mothers probably did not discuss e-mail etiquette, so we have to educate ourselves and our students to be good citizens of cyberspace. 
One final thought, some would disagree, but we think that e-mail messages, both those we send and those our students send, should exhibit proper English usage, with correct spelling, punctuation and capitalization.

Figure 2: E-Mail Fundamentals

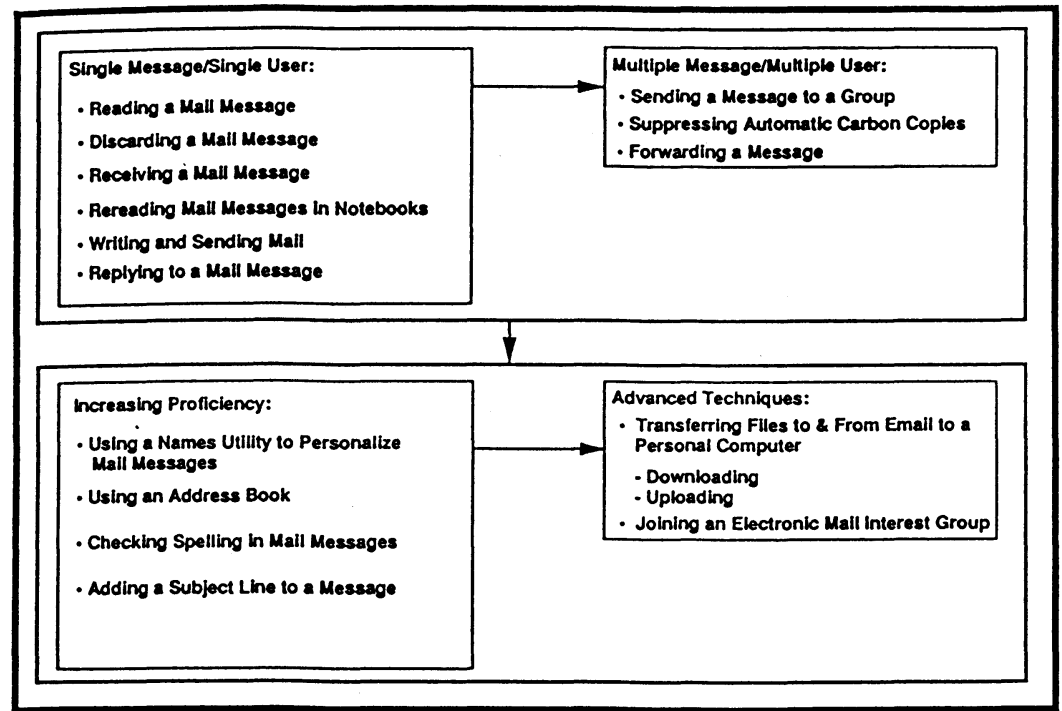

